\title{
Alopecia areata: a new treatment plan
}

This article was published in the following Dove Press journal:

Clinical, Cosmetic and Investigational Dermatology

20 July $201 \mathrm{I}$

Number of times this article has been viewed

\section{Adel Alsantali \\ Department of Dermatology, King Fahd Armed Forces Hospital, Jeddah, Saudi Arabia}

Correspondence: Adel Alsantali Hair Disorders Unit, Department of Dermatology, King Fahd Armed Forces Hospital, PO Box 5389, 3 Jeddah 21593, Saudi Arabia

Tel +96626653000 Ext 2668

Fax +96626638936

Email santli26@hotmail.com
Abstract: Many therapeutic modalities have been used to treat alopecia areata, with variable efficacy and safety profiles. Unfortunately, none of these agents is curative or preventive. Also, many of these therapeutic agents have not been subjected to randomized, controlled trials, and, except for topical immunotherapy, there are few published studies on long-term outcomes. The treatment plan is designed according to the patient's age and extent of disease. In this paper, the therapeutic agents are organized according to their efficacy and safety profiles into first-line, second-line, and third-line options.

Keywords: alopecia areata, corticosteroids, immunotherapy, intralesional, phototherapy, sulfasalazine

\section{Introduction}

Alopecia areata is a common, nonscarring, autoimmune disease that can affect any hair-bearing area. Alopecia areata is a lymphocyte cell-mediated inflammatory type of hair loss, but its pathogenesis is not fully understood. The disease can present as a single, well demarcated patch of hair loss, multiple patches, or extensive hair loss in a form of total loss of scalp hair (alopecia totalis) or loss of entire scalp and body hair (alopecia universalis). A number of treatments can induce hair regrowth in alopecia areata but do not change the course of the disease. Treatment is more effective in patchy alopecia areata than in alopecia totalis/alopecia universalis. Therapy for alopecia areata should be tailored in light of severity of the condition and the patient's age. This review discusses the therapeutic options and management strategies for alopecia areata.

\section{First-line therapies Intralesional corticosteroids}

Several studies have shown the efficacy of intralesional corticosteroid injections. Abell and Munro reported hair regrowth in $71 \%$ of patients with subtotal alopecia areata treated by triamcinolone acetonide injections and in $7 \%$ of a placebo group. ${ }^{1}$ For limited scalp alopecia areata, intralesional corticosteroid therapy is considered as the drug of choice by many experts. The most widely used agent is triamcinolone acetonide. Different concentrations of triamcinolone acetonide are used, in the range of $2.5-10 \mathrm{mg} / \mathrm{mL}$, but $5 \mathrm{mg} / \mathrm{mL}$ is the preferred concentration for the scalp and face. A maximum volume of $3 \mathrm{~mL}$ on the scalp in one visit is recommended. Corticosteroid is injected into the deep dermis level or just beneath the dermis in the upper subcutis. The injections can be repeated at 4-6 weekly intervals. The use 
of mesotherapy multi-injectors with 5-7 needles is an alternative approach to decrease injection pain and to make the procedure more homogenous. ${ }^{2}$ Side effects include skin atrophy and telangiectasia which can be minimized by the use of smaller volumes and avoiding superficial injections. To alleviate injection pain, topical anesthetic may be applied 30-60 minutes before the treatment. Although the effect of a single intralesional corticosteroid injection has been observed to persist for up to 9 months, ${ }^{3}$ reported relapse rates were $29 \%$ in limited alopecia areata and $72 \%$ in alopecia totalis during a 3-month follow-up period. ${ }^{1}$

\section{Topical corticosteroids}

Many forms of topical corticosteroids have been prescribed for alopecia areata, including creams, gels, ointments, lotions, and foams. Sixty-one percent of patients using $0.1 \%$ betamethasone valerate foam achieved more than $75 \%$ hair regrowth in comparison with $27 \%$ in the $0.05 \%$ betamethasone dipropionate lotion group. ${ }^{4}$ Topical corticosteroids are far less effective in alopecia totalis and alopecia universalis. ${ }^{5}$ A highly potent topical corticosteroid under occlusion is the preferred method when using topical corticosteroids. Folliculitis is a common side effect to topical corticosteroids. Telangiectasia and atrophy may develop rarely. The reported relapse rate is $37 \%-63 \%$.

\section{Minoxidil}

In a placebo-controlled, double-blind study, hair regrowth was observed in $63.6 \%$ and $35.7 \%$ of the minoxidil-treated and placebo groups, respectively. ${ }^{7}$ However, only $27 \%$ of the minoxidil-treated patients showed cosmetically acceptable hair regrowth. In another study, hair regrowth was achieved in $38 \%$ and $81 \%$ of patients treated with $1 \%$ and $5 \%$ topical minoxidil, respectively. ${ }^{8}$ Most studies have shown no beneficial effect of topical minoxidil in alopecia totalis and alopecia universalis. ${ }^{9}$ Minoxidil 5\% solution or foam is frequently used with other therapeutic agents as an adjuvant therapy. The adverse effects of topical minoxidil include contact dermatitis and facial hypertrichosis.

\section{Anthralin}

A few controlled trials have assessed the efficacy of topical anthralin in the treatment of alopecia areata. In an open study, a cosmetic response was seen in $25 \%$ of patients with severe alopecia areata treated using $0.5 \%-1.0 \%$ anthralin cream. ${ }^{10}$ In another trial, combination therapy of 5\% minoxidil and $0.5 \%$ anthralin was used to treat 51 patients with severe alopecia areata; only $11 \%$ of patients achieved cosmetically acceptable hair regrowth. ${ }^{11}$ Anthralin needs to be applied in a high enough concentration $(0.5 \%-1 \%)$ and sufficiently frequently (daily) to produce a mild irritant reaction in order to be effective. Severe irritation and staining of skin and clothes are some of the possible adverse events with anthralin.

\section{Topical immunotherapy}

Topical sensitizers that have been used in the treatment of alopecia areata include diphenylcyclopropenone, squaric acid dibutylester (SADBE), and dinitrochlorobenzene. Dinitrochlorobenzene is no longer used because it was shown to be mutagenic in the Ames test. ${ }^{12}$ Diphenylcyclopropenone is the topical sensitizer of choice. SADBE is expensive and not stable in acetone. ${ }^{13}$ Diphenylcyclopropenone is lightsensitive and should be protected from light. ${ }^{14}$

Initially the patient is sensitized using a $2 \%$ solution of diphenylcyclopropenone applied to a $4 \times 4 \mathrm{~cm}$ area of the scalp. After two weeks, $0.001 \%$ diphenylcyclopropenone solution is applied to the same half of the scalp. The diphenylcyclopropenone concentration is increased gradually every week until mild dermatitis is observed. ${ }^{15}$ The solution should be on the scalp for 48 hours. The scalp should be protected from the sun during this time. Once hair regrowth is obtained on the treated half of the scalp, both sides are treated. Both sides of the scalp can be treated from the start also. Diphenylcyclopropenone is applied on a weekly basis by a trained nurse. If there is no response after 6 months of treatment, diphenylcyclopropenone can be discontinued. SADBE may be tried in poor responders to diphenylcyclopropenone or in those who do not develop a sensitization to $2 \%$ diphenylcyclopropenone. SADBE is applied once or twice per week. ${ }^{16,17}$ The adverse effects to topical sensitizers include cervical lymphadenopathy, a severe eczematous reaction, urticaria, and postinflammatory pigment changes. ${ }^{18,19}$

The response rate of alopecia totalis/alopecia universalis patients to diphenylcyclopropenone was $17.4 \%$ in the largest reported diphenylcyclopropenone study, whereas the cumulative patient response was $77 \%{ }^{20}$ Several negative prognostic factors in the treatment of alopecia areata with diphenylcyclopropenone have been suggested, including long duration of disease, alopecia totalis/alopecia universalis, nail changes, atopy, and family history of alopecia areata. ${ }^{20-22}$ Recurrence of alopecia areata after achieving significant hair regrowth developed in $62.6 \%$ of patients. ${ }^{20}$ In a retrospective study of 121 patients with extensive alopecia areata, fexofenadine hydrochloride has been shown to enhance the efficacy of topical immunotherapy. ${ }^{23}$ 
The mechanism of action of topical sensitizers could be due to perifollicular lymphocyte apoptosis, ${ }^{24}$ changes in the peribulbar CD4/CD8 lymphocyte ratio, ${ }^{25,26}$ and antigenic competition. $^{27}$

\section{Prostaglandin analogs}

Eyelash hypertrichosis is a common adverse effect to the use of these antiglaucoma eye drops. ${ }^{28-30}$ Some case series did not show an effect in the treatment of eyelashes in patients with alopecia areata. ${ }^{31,32}$ In a nonrandomized, controlled study of latanoprost (a prostaglandin F2 $\alpha$ analog) eye drops in patients with alopecia universalis, acceptable results (total and moderate hair regrowth) were achieved in $45 \%$ of patients. ${ }^{33}$ In another retrospective trial, $0.03 \%$ bimatoprost eye drops were used once a day for one year. Complete regrowth of the eyelashes was noted in $24.3 \%$ of patients and moderate growth in $18.9 \%$ of treated subjects. ${ }^{34}$ Relapses were observed in $17.5 \%$ of the patients, mainly in the slight response group. ${ }^{33}$

\section{Topical retinoids}

In a comparative study of topical tretinoin $0.05 \%$, topical betamethasone dipropionate lotion, and dithranol paste $0.25 \%$, a good response has been seen in $55 \%$ of patients treated with topical tretinoin in comparison with $70 \%$ and $35 \%$ in the topical steroid and dithranol groups, respectively. ${ }^{35}$ Although the mechanism for its action in alopecia areata is not completely understood, the associated tretinoin-induced dermatitis might contribute to regrowth in alopecia areata. Larger, double-blind, placebo-controlled trials are needed.

\section{Bexarotene}

In a randomized bilateral half-head study, hair regrowth of at least $50 \%$ on treated sites was noticed in only $26 \%$ of patients treated with $1 \%$ bexarotene gel. ${ }^{36}$ Mild irritation is a common side effect.

\section{Capsaicin}

In a nonblinded randomized study, $9.5 \%$ of patients with alopecia areata showed cosmetically acceptable hair regrowth after 12 weeks of applying capsaicin ointment. ${ }^{37}$

\section{Second-line therapies Sulfasalazine}

Sulfasalazine is a combination of sulfapyridine and 5 -aminosalicylic acid linked by a diazo bond. Sulfasalazine has both immunomodulatory and immunosuppressive actions that include suppression of $\mathrm{T}$ cell proliferation and reducing the synthesis of cytokines, including interleukin (IL) 6, 1, and 12 , tumor necrosis factor alpha, and antibody production. ${ }^{38}$ Sulfasalazine has been used safely as a long-term treatment of various inflammatory and autoimmune diseases, including inflammatory bowel disease and rheumatoid arthritis. Several case reports and case series showed good hair regrowth with sulfasalazine in the treatment of alopecia areata.

In an uncontrolled prospective trial of sulfasalazine in 39 patients with persistent alopecia areata, hair regrowth of more than $60 \%$ was achieved in $25.6 \%$ of patients. A moderate response was seen in $30.7 \%$ of patients..$^{39}$ Also, in another uncontrolled open-label study, complete hair regrowth was reported in $27.3 \%$ of subjects. ${ }^{40}$ Sulfasalazine was started at $500 \mathrm{mg}$ twice daily for one month, $1 \mathrm{~g}$ twice daily for one month, and then $1 \mathrm{~g}$ three times daily. ${ }^{41}$ Side effects to sulfasalazine include gastrointestinal distress, dizziness, and headache. ${ }^{39}$ Gastrointestinal symptoms can be minimized by using enteric-coated tablets, taking the medication with food, and starting at lower doses. Initially, patients should have a complete blood count, liver function tests, creatinine, and glucose-6-phosphate dehydrogenase level measurement. Complete blood counts and liver function tests should be performed at 2-4-week intervals during the first three months of therapy. The reported relapse rates are $22.7 \%-45.5 \% .{ }^{39,40}$

\section{Photochemotherapy}

The success rate for oral and topical psoralen plus ultraviolet A (PUVA) ranged from $15 \%$ to more than $70 \% .{ }^{42,43}$ PUVAturban is a method of administering a dilute psoralen solution (8-methoxypsoralen $0.0001 \%$ ) selectively to the scalp for 20 minutes using a cotton towel as a turban. The patient's scalp is then exposed to ultraviolet A radiation. ${ }^{44}$ Treatment sessions are performed two or three times per week. PUVA-turban has been shown to be effective in about $70 \%$ of treated patients. ${ }^{44,45}$ During a follow-up period of 15 months after PUVA-turban therapy, recurrences of alopecia areata were observed in $26 \%$ of responders. ${ }^{44}$ PUVA-turban therapy lacks the systemic side effects of oral PUVA and can be considered as alternative therapy for patients with alopecia areata.

\section{Excimer laser}

In a treatment of 42 alopecia areata patches with the $308 \mathrm{~nm}$ excimer laser, hair regrowth was observed in $41.5 \%$ of treated areas. ${ }^{46}$ Hair regrowth was noticed to begin to appear during the second month of therapy. No regrowth of hair was noted on the control patches. Laser therapy was administered twice 
a week for a maximum of 24 sessions. Apart from erythema at the treated sites, there were no significant adverse effects. Relapses of alopecia areata were observed in two patients with patchy alopecia areata of the scalp who had shown complete regrowth earlier. Also, the use of excimer laser in children with alopecia areata has been reported to have a good success rate. ${ }^{47}$

\section{Fractional photothermolysis laser}

Good hair regrowth was achieved with fractional Er: Glass laser in a single case report. ${ }^{48}$ Randomized controlled trials in a larger number of patients are required to confirm the efficacy of this modality of treatment.

\section{Third-line therapies Systemic corticosteroids}

Systemic corticosteroids are one of the commonly prescribed therapies in patients with extensive alopecia areata. Various forms of corticosteroids have been used in different regimens. In one study, a once-monthly oral pulse of $300 \mathrm{mg}$ prednisone induced a complete response in $41 \%$ of patients. ${ }^{49}$ A similar effect has been reported in a placebocontrolled trial of oral prednisolone $200 \mathrm{mg}$ once weekly in the treatment of extensive alopecia areata. ${ }^{50}$ The relapse rate was $25 \%$, and side effects of the therapy were noted in $55 \%$ of patients. ${ }^{50}$ In a comparative trial, the response rate was better in patients treated with intramuscular triamcinolone acetonide $40 \mathrm{mg}$ once monthly than in those treated with oral dexamethasone $0.5 \mathrm{mg} / \mathrm{day} .{ }^{51} \mathrm{In}$ the same study, impairment of adrenocortical reserve was seen in $23 \%$ of the intramuscular triamcinolone acetonide group and in $7 \%$ of patients treated with oral prednisolone pulse therapy of $80 \mathrm{mg}$ for 3 consecutive days once every 3 months. In a study of 139 patients treated with pulse corticosteroid therapy, a good response was achieved in $59.4 \%$ of patients with recent-onset disease (duration of alopecia areata up to 6 months) in comparison with $15.8 \%$ of subjects who had had alopecia areata for more than 6 months. ${ }^{52}$ Alopecia totalis and alopecia universalis are far less responsive to this therapy than patchy alopecia areata. ${ }^{53}$ The use of systemic corticosteroids is limited by their side effects (hyperglycemia, weight gain, hypertension, adrenal suppression, dysmenorrhea, immunosuppression, and acneiform eruption $)^{50,54}$ and the high relapse rate $(14 \%-100 \%) .{ }^{51,55,56}$

\section{Methotrexate}

In a long-term follow-up study of methotrexate in 33 patients with alopecia areata, complete hair regrowth was achieved in $57 \%$ and $63 \%$ of patients who used methotrexate alone or with low doses of oral corticosteroids (prednisone 10-20 mg/day), respectively. ${ }^{57}$ Thirty percent of patients had partial hair regrowth. The weekly dosages of methotrexate were 15-25 mg. The onset of hair regrowth was seen after a median delay of three months. Recurrences of alopecia areata after a decrease of the methotrexate dose or after stopping treatment were observed in 57\% (8/14 cases) of responders. In a retrospective trial of methotrexate in 14 children with alopecia areata, approximately one third of patients experienced a clinically relevant therapeutic response. ${ }^{58}$ The mean age of the patients was 14.7 (range 8-18) years. Adverse effects to methotrexate include persistent nausea, transient elevation of hepatic enzymes, and leucopenia.

\section{Cyclosporine}

The success rate with oral cyclosporine is $25 \%-76.6 \%{ }^{59,60}$ A recent study showed that a good response to oral cyclosporine can be predicted if the serum level of IL 18 is elevated and the level of soluble IL 2 receptor is low. ${ }^{61}$ The use of oral cyclosporine in patients with alopecia areata is not generally favored due to its adverse event profile (nephrotoxicity, immune suppression, and hypertension) and a high relapse rate (up to $100 \%$ ). ${ }^{62}$ Also, alopecia areata incidence has been reported in several organ transplant patients receiving cyclosporine. ${ }^{63-66}$ Although hypertrichosis is a documented side effect of oral cyclosporine, ${ }^{67}$ a good response has not been achieved by using topical cyclosporine in humans. ${ }^{68,69}$

\section{Azathioprine}

Azathioprine, a thiopurine analog immunosuppressive drug, has been used to treat a vast array of autoimmune diseases. It inhibits DNA synthesis and thus decreases proliferation of cells, especially $\mathrm{T}$ and B lymphocytes. Azathioprine also decreases the number of Langerhans cells and other antigen-presenting cells in the skin. In a recent pilot study of 20 patients treated with azathioprine $2 \mathrm{mg} / \mathrm{kg} /$ day as monotherapy, mean hair regrowth was $52.3 \% \pm 38.4 \% .{ }^{70}$ These results need to be confirmed in large-scale, randomized, controlled studies.

\section{Biologics}

Although tumor necrosis factor alpha is implicated in the pathogenesis of alopecia areata, there are several reported cases that have shown either development of alopecia areata or complete failure to respond to different tumor necrosis factor alpha inhibitors, including adalimumab, ${ }^{71,74}$ infliximab, ${ }^{75,76}$ and etanercept. ${ }^{77-79}$ In a prospective trial of 
17 patients with alopecia areata, Strober et al concluded that etanercept does not effectively treat moderate to severe alopecia areata. ${ }^{80}$ Also, in a placebo-controlled study, Price et al showed that efalizumab, an anti-CD11a antibody, is not effective in the treatment of alopecia areata. ${ }^{81}$ Some clinical trials are ongoing to evaluate the efficacy of the newer biologic therapies in the treatment of alopecia areata.

\section{Psychological support}

Alopecia areata is considered to be an example of a psychosomatic disorder, leading to dramatic and devastating emotions which can negatively impact patient self-esteem, body image, and self-confidence. ${ }^{82}$

One important step that should not be overlooked during the course of management of alopecia areata is offering psychological support to foster increased self-esteem and adaptation to this disease. Helping patients with alopecia areata cope with depression and an unpredictable disease like alopecia areata can be achieved by several ways, including education of the patient about the nature of disease, psychotherapy, hypnotherapy, ${ }^{83}$ antidepressants, ${ }^{84,85}$ and support groups. Hypnotherapy may significantly improve depression, anxiety, and quality of life, but not hair regrowth. ${ }^{86}$ Patients with extensive disease may wear scalp prostheses, such as wigs, hairpieces, or other scalp coverings.

\section{Other therapies}

Other therapeutic agents have been tried, with some degree of success. These modalities include aromatherapy, ${ }^{87}$ a combination of topical garlic gel and betamethasone valerate cream, ${ }^{88}$ topical azelic acid, ${ }^{89}$ oral zinc supplementation,,${ }^{90-92}$ topical onion juice, ${ }^{93}$ a simvastatin-ezetimibe combination, ${ }^{94,95}$ inosiplex, ${ }^{96-98}$ and intralesional injections of candida antigen. ${ }^{99}$

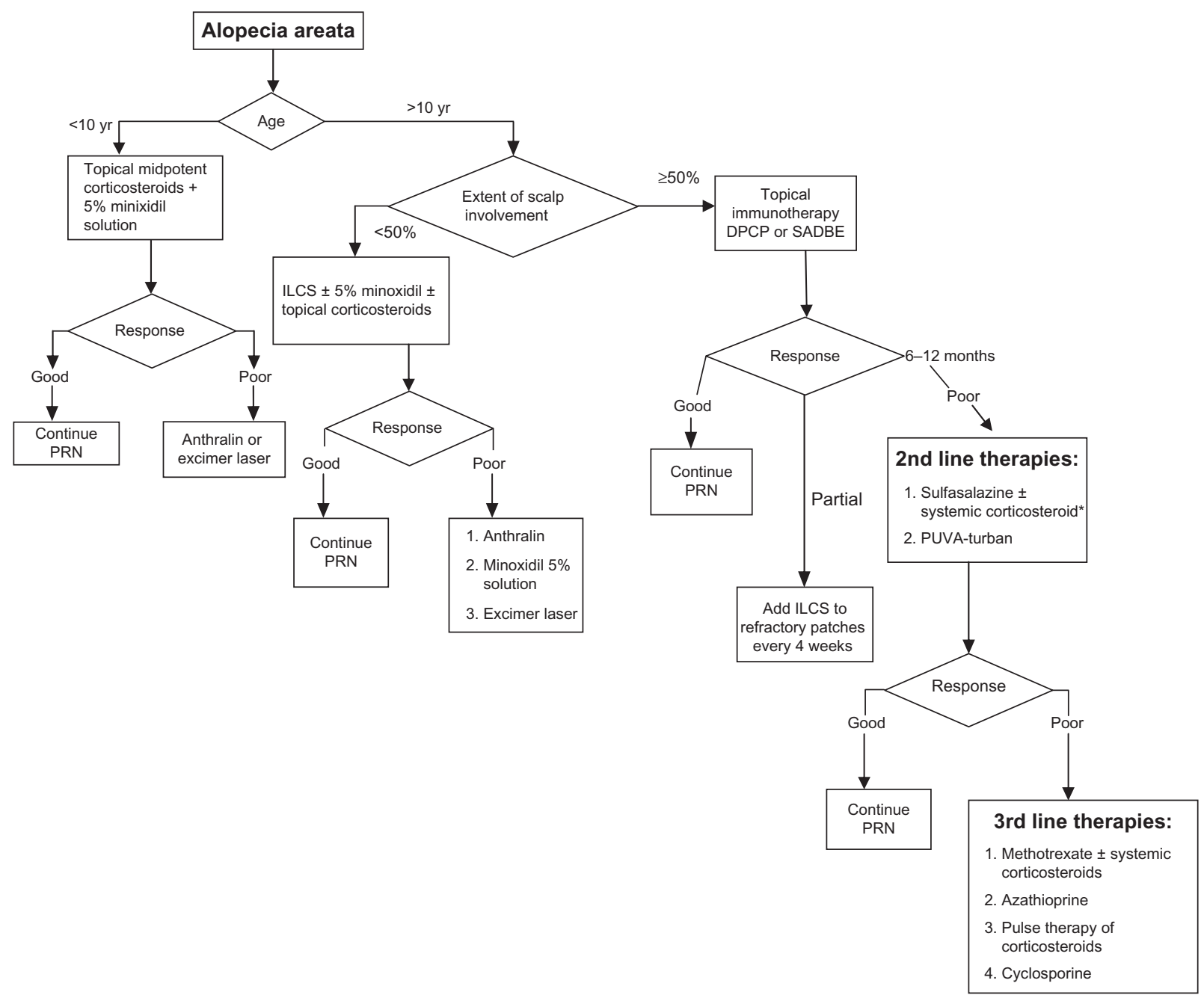

Figure I Treatment plan for AA.

Note: *Systemic Corticosteroids are used as a bridge therapy.

Abbreviations: DPCP, diphenylcyclopropenone; ILCS, intralesional corticosteroids; PRN, as needed; SADBE, squaric acid dibutylester. 
These treatment modalities need to be confirmed in largescale, double-blind, placebo-controlled trials.

There are other modalities of therapy that have not shown good efficacy. These agents include imiquimod, ${ }^{100,101}$ topical calcineurin inhibitors, ${ }^{102-106}$ botulinum toxin type $\mathrm{A},{ }^{107}$ topical tri-iodothyronine ointment, ${ }^{108}$ photodynamic therapy, ${ }^{109-111}$ and topical 5-fluorounacil. ${ }^{112}$

\section{Management plan}

Treatment options should be selected according to patient age and extent of disease. For patients younger than 10 years, a combination of $5 \%$ minoxidil solution twice daily with midpotent corticosteroids should be tried first. If there is no good improvement after 6 months, short-contact anthralin is considered as second-line therapy. Excimer laser can be used, particularly in patchy alopecia areata.

For patients older than 10 years of age with alopecia areata involving less than $50 \%$ of the scalp, intralesional triamcinolone acetonide injection $(5 \mathrm{mg} / \mathrm{cc})$ is the recommended option for treatment. If there is no good response after 6 months, other options can be tried, including potent topical corticosteroids under occlusion at night, $5 \%$ topical minoxidil twice a day, short-contact anthralin, and excimer laser.

If alopecia areata involves more than $50 \%$ of the scalp, topical immunotherapy with diphenylcyclopropenone is the first therapeutic option recommended by many experts in hair diseases. Intralesional injections of triamcinolone acetonide are used to treat persistent alopecic patches.

For patients who respond poorly to diphenylcyclopropenone and those who cannot use it, second-line therapies can be used. Several reviews of alopecia areata therapy suggest topical minoxidil and topical corticosteroids ${ }^{113-116}$ but, as discussed earlier, the yield of these topical agents in the treatment of extensive alopecia areata is limited. Therefore, we suggest that patients with extensive resistant disease can use sulfasalazine with or without systemic corticosteroids. Systemic steroids are used as bridge therapy until the sulfasalazine takes effect. Treatment with sulfasalazine is generally well tolerated and characterized by a lower incidence of serious side effects in comparison with other systemic therapies like corticosteroids and methotrexate. The other second-line therapy is PUVAturban. It is a well tolerated therapy with minimal local phototoxic side effects and without the systemic side effects of PUVA. These options are selected based on a balance between the efficacy and safety of these therapeutic agents.

If these therapies fail or are not tolerated, third-line therapeutic options can be discussed with patients in terms of the expected outcome of therapy and possible side effects.
These agents include methotrexate with or without a systemic corticosteroid, azathioprine, cyclosporine, and pulse therapy of corticosteroids. While using these drugs, close monitoring of patients is important to avoid possible side effects. A summary of an alopecia areata treatment plan is shown as an algorithmic approach in Figure 1.

\section{Disclosure}

The author reports no conflicts of interest in this work.

\section{References}

1. Abell E, Munro DD. Intralesional treatment of alopecia areata with triamcinolone acetonide by jet injector. Br J Dermatol. 1973;88(1):55-59.

2. Ferrando J, Moreno-Arias GA. Multi-injection plate for intralesional corticosteroid treatment of patchy alopecia areata. Dermatol Surg. 2000; 26(7):690-691.

3. Orentreich N, Sturm HM, Weidman AI, Pelzig A. Local injection of steroids and hair regrowth in alopecias. Arch Dermatol. 1960;82: 894-902.

4. Mancuso G, Balducci A, Casadio C, et al. Efficacy of betamethasone valerate foam formulation in comparison with betamethasone dipropionate lotion in the treatment of mild-to-moderate alopecia areata: a multicenter, prospective, randomized, controlled, investigator-blinded trial. Int J Dermatol. 2003;42(7):572-575.

5. Tosti A, Piraccini BM, Pazzaglia M, Vincenzi C. Clobetasol propionate $0.05 \%$ under occlusion in the treatment of alopecia totalis/universalis. J Am Acad Dermatol. 2003;49(1):96-98.

6. Pascher F, Kurtin S, Andrade R. Assay of 0.2 percent fluocinolone acetonide cream for alopecia areata and totalis. Efficacy and side effects including histologic study of the ensuing localized acneform response. Dermatologica. 1970;141(3):193-202.

7. Price VH. Double-blind, placebo-controlled evaluation of topical minoxidil in extensive alopecia areata. J Am Acad Dermatol. 1987;16(3 Pt 2): 730-736.

8. Fiedler-Weiss VC. Topical minoxidil solution (1\% and $5 \%)$ in the treatment of alopecia areata. J Am Acad Dermatol. 1987;16(3 Pt 2): 745-748.

9. Price VH. Topical minoxidil (3\%) in extensive alopecia areata, including long-term efficacy. J Am Acad Dermatol. 1987;16(3 Pt 2):737-744.

10. Fiedler-Weiss VC, Buys CM. Evaluation of anthralin in the treatment of alopecia areata. Arch Dermatol. 1987;123(11):1491-1493.

11. Fiedler VC, Wendrow A, Szpunar GJ, Metzler C, DeVillez RL. Treatment-resistant alopecia areata. Response to combination therapy with minoxidil plus anthralin. Arch Dermatol. 1990;126(6):756-759.

12. Strobel R, Rohrborn G. Mutagenic and cell transforming activities of 1-chlor-2,4-dinitrobenzene (DNCB) and squaric-acid-dibutylester (SADBE). Arch Toxicol. 1980;45(4):307-314.

13. Wilkerson MG, Henkin J, Wilkin JK, Smith RG. Squaric acid and esters: analysis for contaminants and stability in solvents. J Am Acad Dermatol. 1985;13(2 Pt 1):229-234.

14. Wilkerson MG, Henkin J, Wilkin JK. Diphenylcyclopropenone: examination for potential contaminants, mechanisms of sensitization, and photochemical stability. J Am Acad Dermatol. 1984;11(5 Pt 1):802-807.

15. Orecchia G, Perfetti L. Alopecia areata and topical sensitizers: allergic response is necessary but irritation is not. $\mathrm{Br} J$ Dermatol. 1991; 124(5):509.

16. Orecchia G, Malagoli P, Santagostino L. Treatment of severe alopecia areata with squaric acid dibutylester in pediatric patients. Pediatr Dermatol. 1994;11(1):65-68.

17. Dall'oglio F, Nasca MR, Musumeci ML, et al. Topical immunomodulator therapy with squaric acid dibutylester (SADBE) is effective treatment for severe alopecia areata (AA): results of an open-label, pairedcomparison, clinical trial. J Dermatolog Treat. 2005;16(1):10-14. 
18. Aghaei S. Topical immunotherapy of severe alopecia areata with diphenylcyclopropenone (DPCP): experience in an Iranian population. BMC Dermatol. 2005;5:6.

19. Francomano M, Seidenari S. Urticaria after topical immunotherapy with diphenylcyclopropenone. Contact Dermatitis. 2002;47(5): 310-311.

20. Wiseman MC, Shapiro J, MacDonald N, Lui H. Predictive model for immunotherapy of alopecia areata with diphencyprone. Arch Dermatol. 2001;137(8):1063-1068.

21. van der Steen PH, van Baar HM, Happle R, Boezeman JB, Perret CM. Prognostic factors in the treatment of alopecia areata with diphenylcyclopropenone. J Am Acad Dermatol. 1991;24(2 Pt 1): 227-230.

22. Weise K, Kretzschmar L, John SM, Hamm H. Topical immunotherapy in alopecia areata: anamnestic and clinical criteria of prognostic significance. Dermatology. 1996;192(2):129-133.

23. Inui $\mathrm{S}$, Nakajima $\mathrm{T}$, Toda $\mathrm{N}$, Itami S. Fexofenadine hydrochloride enhances the efficacy of contact immunotherapy for extensive alopecia areata: retrospective analysis of 121 cases. J Dermatol. 2009;36(6): 323-327.

24. Herbst V, Zoller M, Kissling S, Wenzel E, Stutz N, FreyschmidtPaul P. Diphenylcyclopropenone treatment of alopecia areata induces apoptosis of perifollicular lymphocytes. Eur J Dermatol. 2006;16(5): 537-542.

25. Happle R, Klein HM, Macher E. Topical immunotherapy changes the composition of the peribulbar infiltrate in alopecia areata. Arch Dermatol Res. 1986;278(3):214-218.

26. Wasylyszyn T, Kozlowski W, Zabielski SL. Changes in distribution pattern of CD8 lymphocytes in the scalp in alopecia areata during treatment with diphencyprone. Arch Dermatol Res. 2007;299(5-6): 231-237.

27. Happle R. Antigenic competition as a therapeutic concept for alopecia areata. Arch Dermatol Res. 1980;267(1):109-114.

28. Bearden W, Anderson R. Trichiasis associated with prostaglandin analog use. Ophthal Plast Reconstr Surg. 2004;20(4):320-322.

29. Hart J, Shafranov G. Hypertrichosis of vellus hairs of the malar region after unilateral treatment with bimatoprost. Am J Ophthalmol. 2004;137(4):756-757.

30. Tosti A, Pazzaglia M, Voudouris S, Tosti G. Hypertrichosis of the eyelashes caused by bimatoprost. J Am Acad Dermatol. 2004;51(Suppl 5): S149-S150.

31. Roseborough I, Lee H, Chwalek J, Stamper RL, Price VH. Lack of efficacy of topical latanoprost and bimatoprost ophthalmic solutions in promoting eyelash growth in patients with alopecia areata. $J$ Am Acad Dermatol. 2009;60(4):705-706.

32. Ross EK, Bolduc C, Lui H, Shapiro J. Lack of efficacy of topical latanoprost in the treatment of eyebrow alopecia areata. J Am Acad Dermatol. 2005;53(6):1095-1096.

33. Coronel-Perez IM, Rodriguez-Rey EM, Camacho-Martinez FM. Latanoprost in the treatment of eyelash alopecia in alopecia areata universalis. J Eur Acad Dermatol Venereol. 2010;24(4):481-485.

34. Vila OT, Camacho Martinez FM. Bimatoprost in the treatment of eyelash universalis alopecia areata. Int J Trichology. 2010;2(2):86-88.

35. Das S, Ghorami RC, Chatterjee T, Banerjee G. Comparative assessment of topical steroids, topical tretenoin $(0.05 \%)$ and dithranol paste in alopecia areata. Indian J Dermatol. 2010;55(2):148-149.

36. Talpur R, Vu J, Bassett R, Stevens V, Duvic M. Phase I/II randomized bilateral half-head comparison of topical bexarotene $1 \%$ gel for alopecia areata. J Am Acad Dermatol. 2009;61(4):592. e591-e599.

37. Ehsani AH, Toosi S, Seirafi H, et al. Capsaicin vs clobetasol for the treatment of localized alopecia areata. J Eur Acad Dermatol Venereol. 2009;23(12):1451-1453.

38. Ranganath VK, Furst DE. Disease-modifying antirheumatic drug use in the elderly rheumatoid arthritis patient. Rheum Dis Clin North Am. 2007;33(1):197-217.

39. Rashidi T, Mahd AA. Treatment of persistent alopecia areata with sulfasalazine. Int J Dermatol. 2008;47(8):850-852.
40. Aghaei S. An uncontrolled, open label study of sulfasalazine in severe alopecia areata. Indian J Dermatol Venereol Leprol. 2008;74(6): 611-613.

41. Ellis CN, Brown MF, Voorhees JJ. Sulfasalazine for alopecia areata. J Am Acad Dermatol. 2002;46(4):541-544.

42. Taylor CR, Hawk JL. PUVA treatment of alopecia areata partialis, totalis and universalis: audit of 10 years' experience at St John's Institute of Dermatology. Br J Dermatol. 1995;133(6):914-918.

43. Mohamed Z, Bhouri A, Jallouli A, Fazaa B, Kamoun MR, Mokhtar I. Alopecia areata treatment with a phototoxic dose of UVA and topical 8-methoxypsoralen. J Eur Acad Dermatol Venereol. 2005;19(5): $552-555$.

44. Broniarczyk-Dyla G, Wawrzycka-Kaflik A, Dubla-Berner M, Prusinska-Bratos M. Effects of psoralen-UV-A-Turban in alopecia areata. Skinmed. 2006;5(2):64-68.

45. Behrens-Williams SC, Leiter U, Schiener R, Weidmann M, Peter RU, Kerscher M. The PUVA-turban as a new option of applying a dilute psoralen solution selectively to the scalp of patients with alopecia areata. $J$ Am Acad Dermatol. 2001;44(2):248-252.

46. Al-Mutairi N. 308-nm excimer laser for the treatment of alopecia areata Dermatol Surg. 2007;33(12):1483-1487.

47. Al-Mutairi N. 308-nm excimer laser for the treatment of alopecia areata in children. Pediatr Dermatol. 2009;26(5):547-550.

48. Yoo KH, Kim MN, Kim BJ, Kim CW. Treatment of alopecia areata with fractional photothermolysis laser. Int J Dermatol. 2010;49(7): $845-847$.

49. Ait Ourhroui M, Hassam B, Khoudri I. Treatment of alopecia areata with prednisone in a once-monthly oral pulse. Ann Dermatol Venereol. 2010;137(8-9):514-518. French.

50. Kar BR, Handa S, Dogra S, Kumar B. Placebo-controlled oral pulse prednisolone therapy in alopecia areata. J Am Acad Dermatol. 2005; 52(2):287-290.

51. Kurosawa M, Nakagawa S, Mizuashi M, et al. A comparison of the efficacy, relapse rate and side effects among three modalities of systemic corticosteroid therapy for alopecia areata. Dermatology. 2006;212(4): $361-365$.

52. Nakajima T, Inui S, Itami S. Pulse corticosteroid therapy for alopecia areata: study of 139 patients. Dermatology. 2007;215(4):320-324.

53. Friedli A, Labarthe MP, Engelhardt E, Feldmann R, Salomon D, Saurat JH. Pulse methylprednisolone therapy for severe alopecia areata: an open prospective study of 45 patients. J Am Acad Dermatol. 1998;39(4 Pt 1):597-602.

54. Lester RS, Knowles SR, Shear NH. The risks of systemic corticosteroid use. Dermatol Clin. 1998;16(2):277-288.

55. Sharma VK, Gupta S. Twice weekly $5 \mathrm{mg}$ dexamethasone oral pulse in the treatment of extensive alopecia areata. J Dermatol. 1999;26(9): $562-565$.

56. Luggen P, Hunziker T. High-dose intravenous corticosteroid pulse therapy in alopecia areata: own experience compared with the literature. J Dtsch Dermatol Ges. 2008;6(5):375-378. German.

57. Chartaux E, Joly P. Long-term follow-up of the efficacy of methotrexate alone or in combination with low doses of oral corticosteroids in the treatment of alopecia areata totalis or universalis. Ann Dermatol Venereol. 2010;137(8-9):507-513. French.

58. Royer M, Bodemer C, Vabres P, et al. Efficacy and tolerability of methotrexate in severe childhood alopecia areata. Br J Dermatol. April 25, 2011. [Epub ahead of print].

59. Shapiro J, Lui H, Tron V, Ho V. Systemic cyclosporine and low-dose prednisone in the treatment of chronic severe alopecia areata: a clinical and immunopathologic evaluation. J Am Acad Dermatol. 1997;36(1): 114-117.

60. Kim BJ, Min SU, Park KY, et al. Combination therapy of cyclosporine and methylprednisolone on severe alopecia areata. J Dermatolog Treat. 2008;19(4):216-220.

61. Lee D, Hong SK, Park SW, et al. Serum levels of IL-18 and sIL-2R in patients with alopecia areata receiving combined therapy with oral cyclosporine and steroids. Exp Dermatol. 2010;19(2):145-147. 
62. Gupta AK, Ellis CN, Cooper KD, et al. Oral cyclosporine for the treatment of alopecia areata. A clinical and immunohistochemical analysis. J Am Acad Dermatol. 1990;22(2 Pt 1):242-250.

63. Phillips MA, Graves JE, Nunley JR. Alopecia areata presenting in 2 kidney-pancreas transplant recipients taking cyclosporine. JAm Acad Dermatol. 2005;53(5 Suppl 1):S252-S255.

64. Dyall-Smith D. Alopecia areata in a renal transplant recipient on cyclosporin. Australas J Dermatol. 1996;37(4):226-227.

65. Cerottini JP, Panizzon RG, de Viragh PA. Multifocal alopecia areata during systemic cyclosporine A therapy. Dermatology. 1999;198(4): 415-417.

66. Davies MG, Bowers PW. Alopecia areata arising in patients receiving cyclosporin immunosuppression. Br J Dermatol. 1995;132(5):835-836.

67. Sternthal MB, Murphy SJ, George J, Kornbluth A, Lichtiger S, Present DH. Adverse events associated with the use of cyclosporine in patients with inflammatory bowel disease. Am J Gastroenterol. 2008;103(4):937-943.

68. Gilhar A, Pillar T, Etzioni A. Topical cyclosporin A in alopecia areata. Acta Derm Venereol. 1989;69(3):252-253.

69. Mauduit G, Lenvers P, Barthelemy H, Thivolet J. Treatment of severe alopecia areata with topical applications of cyclosporin A. Ann Dermatol Venereol. 1987;114(4):507-510. French.

70. Farshi S, Mansouri P, Safar F, Khiabanloo SR. Could azathioprine be considered as a therapeutic alternative in the treatment of alopecia areata? a pilot study. Int J Dermatol. 2010;49(10):1188-1193.

71. Garcia Bartels N, Lee HH, Worm M, Burmester GR, Sterry W, BlumePeytavi U. Development of alopecia areata universalis in a patient receiving adalimumab. Arch Dermatol. 2006;142(12):1654-1655.

72. Kirshen C, Kanigsberg N. Alopecia areata following adalimumab. J Cutan Med Surg. 2009;13(1):48-50.

73. Chaves Y, Duarte G, Ben-Said B, Tebib J, Berard F, Nicolas JF. Alopecia areata universalis during treatment of rheumatoid arthritis with antiTNF-alpha antibody (adalimumab). Dermatology. 2008;217(4):380.

74. Pelivani N, Hassan AS, Braathen LR, Hunger RE, Yawalkar N. Alopecia areata universalis elicited during treatment with adalimumab. Dermatology. 2008;216(4):320-323.

75. Ettefagh L, Nedorost S, Mirmirani P. Alopecia areata in a patient using infliximab: new insights into the role of tumor necrosis factor on human hair follicles. Arch Dermatol. 2004;140(8):1012.

76. Fabre $\mathrm{C}$, Dereure $\mathrm{O}$. Worsening alopecia areata and de novo occurrence of multiple halo nevi in a patient receiving infliximab. Dermatology. 2008;216(2):185-186.

77. Posten W, Swan J. Recurrence of alopecia areata in a patient receiving etanercept injections. Arch Dermatol. 2005;141(6):759-760.

78. Abramovits W, Losornio M. Failure of two TNF-alpha blockers to influence the course of alopecia areata. Skinmed. 2006;5(4):177-181.

79. Pan Y, Rao NA. Alopecia areata during etanercept therapy. Ocul Immunol Inflamm. 2009;17(2):127-129.

80. Strober BE, Siu K, Alexis AF, et al. Etanercept does not effectively treat moderate to severe alopecia areata: an open-label study. $J \mathrm{Am}$ Acad Dermatol. 2005;52(6):1082-1084.

81. Price VH, Hordinsky MK, Olsen EA, et al. Subcutaneous efalizumab is not effective in the treatment of alopecia areata. $J$ Am Acad Dermatol. 2008;58(3):395-402.

82. Ruiz-Doblado S, Carrizosa A, Garcia-Hernandez MJ. Alopecia areata: psychiatric comorbidity and adjustment to illness. Int J Dermatol. 2003; 42(6):434-437.

83. Willemsen R, Vanderlinden J, Deconinck A, Roseeuw D. Hypnotherapeutic management of alopecia areata. J Am Acad Dermatol. 2006;55(2): 233-237.

84. Cipriani R, Perini GI, Rampinelli S. Paroxetine in alopecia areata. Int J Dermatol. 2001;40(9):600-601.

85. Perini G, Zara M, Cipriani R, et al. Imipramine in alopecia areata. A double-blind, placebo-controlled study. Psychother Psychosom. 1994;61(3-4):195-198.
86. Willemsen R, Haentjens P, Roseeuw D, Vanderlinden J. Hypnosis in refractory alopecia areata significantly improves depression, anxiety, and life quality but not hair regrowth. JAm Acad Dermatol. 2010;62(3): $517-518$.

87. Hay IC, Jamieson M, Ormerod AD. Randomized trial of aromatherapy. Successful treatment for alopecia areata. Arch Dermatol. 1998;134(11):1349-1352.

88. Hajheydari Z, Jamshidi M, Akbari J, Mohammadpour R. Combination of topical garlic gel and betamethasone valerate cream in the treatment of localized alopecia areata: a double-blind randomized controlled study. Indian J Dermatol Venereol Leprol. 2007;73(1):29-32.

89. Sasmaz S, Arican O. Comparison of azelaic acid and anthralin for the therapy of patchy alopecia areata: a pilot study. Am J Clin Dermatol. 2005;6(6):403-406.

90. Park H, Kim CW, Kim SS, Park CW. The therapeutic effect and the changed serum zinc level after zinc supplementation in patients with alopecia areata who had a low serum zinc level. Ann Dermatol. 2009; 21(2):142-146.

91. Bhat YJ, Manzoor S, Khan AR, Qayoom S. Trace element levels in alopecia areata. Indian J Dermatol Venereol Leprol. 2009;75(1):29-31.

92. Lutz G, Kreysel HW. Selective changes in lymphocytic differentiation antigens in the peripheral blood of patients with alopecia areata treated with oral zinc. Z Hautkr. 1990;65(2):132-134. German.

93. Sharquie KE, Al-Obaidi HK. Onion juice (Allium cepa L.), a new topical treatment for alopecia areata. J Dermatol. 2002;29(6):343-346.

94. Robins DN. Case reports: alopecia universalis: hair growth following initiation of simvastatin and ezetimibe therapy. J Drugs Dermatol. 2007;6(9):946-947.

95. Ali A, Martin JM 4th. Hair growth in patients alopecia areata totalis after treatment with simvastatin and ezetimibe. J Drugs Dermatol. 2010;9(1):62-64.

96. Galbraith GM, Thiers BH, Jensen J, Hoehler F. A randomized doubleblind study of inosiplex (isoprinosine) therapy in patients with alopecia totalis. J Am Acad Dermatol. 1987;16(5 Pt 1):977-983.

97. Georgala S, Katoulis AC, Befon A, Georgala K, Stavropoulos PG. Inosiplex for treatment of alopecia areata: a randomized placebocontrolled study. Acta Derm Venereol. 2006;86(5):422-424.

98. Lowy M, Ledoux-Corbusier M, Achten G, Wybran J. Clinical and immunologic response to isoprinosine in alopecia areata and alopecia universalis: association with autoantibodies. $J$ Am Acad Dermatol. 1985;12(1 Pt 1):78-84.

99. Rosenberg EW, Skinner RB Jr. Immunotherapy of alopecia areata with intralesional Candida antigen. Pediatr Dermatol. 2006;23(3):299.

100. D’Ovidio R, Claudatus J, Di Prima T. Ineffectiveness of imiquimod therapy for alopecia totalis/universalis. J Eur Acad Dermatol Venereol. 2002;16(4):416-417.

101. Koc E, Tunca M, Akar A, Kurumlu Z. Lack of efficacy of topical imiquimod in the treatment of patchy alopecia areata. Int J Dermatol. 2008;47(10):1088-1089.

102. Rigopoulos D, Gregoriou S, Korfitis C, et al. Lack of response of alopecia areata to pimecrolimus cream. Clin Exp Dermatol. 2007;32(4): 456-457.

103. Feldmann KA, Kunte C, Wollenberg A, Wolfe H. Is topical tacrolimus effective in alopecia areata universalis? Br J Dermatol. 2002;147(5): 1031-1032.

104. Park SW, Kim JW, Wang HY. Topical tacrolimus (FK506): treatment failure in four cases of alopecia universalis. Acta Derm Venereol. 2002;82(5):387-388.

105. Price VH, Willey A, Chen BK. Topical tacrolimus in alopecia areata. J Am Acad Dermatol. 2005;52(1):138-139.

106. Thiers BH. Topical tacrolimus: treatment failure in a patient with alopecia areata. Arch Dermatol. 2000;136(1):124.

107. Cho HR, Lew BL, Lew H, Sim WY. Treatment effects of intradermal botulinum toxin type A injection on alopecia areata. Dermatol Surg. 2010;36(Suppl 4):2175-2181. 
108. Nasiri S, Haghpanah V, Taheri E, Heshmat R, Larijani B, Saeedi M. Hair regrowth with topical triiodothyronine ointment in patients with alopecia areata: a double-blind, randomized pilot clinical trial of efficacy. J Eur Acad Dermatol Venereol. 2011 Apr 27. [Epub ahead of print].

109. Yoo KH, Lee JW, Li K, Kim BJ, Kim MN. Photodynamic therapy with methyl 5-aminolevulinate acid might be ineffective in recalcitrant alopecia totalis regardless of using a microneedle roller to increase skin penetration. Dermatol Surg. 2010;36(5):618-622.

110. Fernandez-Guarino M, Harto A, Garcia-Morales I, Perez-Garcia B, Arrazola JM, Jaen P. Failure to treat alopecia areata with photodynamic therapy. Clin Exp Dermatol. 2008;33(5):585-587.

111. Bissonnette R, Shapiro J, Zeng H, McLean DI, Lui H. Topical photodynamic therapy with 5-aminolaevulinic acid does not induce hair regrowth in patients with extensive alopecia areata. Br J Dermatol. 2000;143(5):1032-1035.
112. Kaplan AL, Olsen EA. Topical 5-fluorouracil is ineffective in the treatment of extensive alopecia areata. J Am Acad Dermatol. 2004;50(6): 941-943.

113. Wasserman D, Guzman-Sanchez DA, Scott K, McMichael A. Alopecia areata. Int J Dermatol. 2007;46(2):121-131.

114. Madani S, Shapiro J. Alopecia areata update. J Am Acad Dermatol. 2000;42(4):549-566.

115. Alkhalifah A, Alsantali A, Wang E, McElwee KJ, Shapiro J. Alopecia areata update: part II. Treatment. J Am Acad Dermatol. 2010;62(2): 191-202.

116. Ross EK, Shapiro J. Management of hair loss. Dermatol Clin. 2005; 23(2):227-243.

\section{Publish your work in this journal}

Clinical, Cosmetic and Investigational Dermatology is an international, peer-reviewed, open access, online journal that focuses on the latest clinical and experimental research in all aspects of skin disease and cosmetic interventions. All areas of dermatology will be covered; contributions will be welcomed from all clinicians and basic science researchers globally. This journal is indexed on CAS. The manuscript management system is completely online and includes a very quick and fair peer-review system, which is all easy to use. Visit http://www.dovepress.com/testimonials.php to read real quotes from published authors.

Submit your manuscript here: http://www.dovepress.com/clinical-cosmetic-and-investigational-dermatology-journal 